\title{
LDL Particles Measurement
}

National Cancer Institute

\section{Source}

National Cancer Institute. LDL Particles Measurement. NCI Thesaurus. Code C120636.

The determination of the LDL particles present in a sample. 